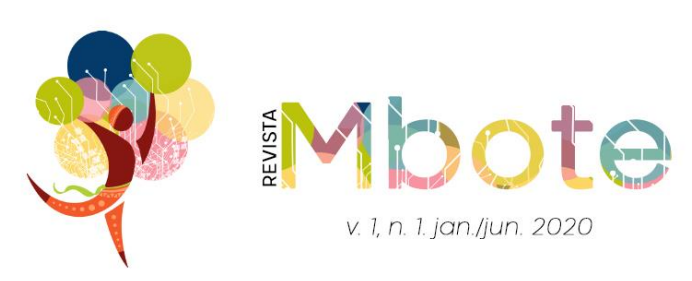

\title{
"A MÃO QUE AFAGA É A MESMA QUE APEDREJA": DIREITO, IMIGRAÇÃO E A PERPETUAÇÃO DO RACISMO ESTRUTURAL NO BRASIL
}

\author{
Karine de Souza SILVA ${ }^{2}$
}

Resumo: Partindo da premissa segundo a qual o Direito é uma tecnologia de controle e racialização de corpos negros (ALMEIDA, 2018), e de manutenção de elites no poder (PIRES, 2019) este artigo objetiva mostrar como a branquitude, enquanto lugar de privilégio sistêmico (SCHUCMAN,) se utilizou de normas e políticas migratórias para perpetuar as vantagens unilaterais do racismo estrutural. A base teórica está assentada nos estudos anti-coloniais, pós-colonais e decolonais porque estes permitem entender como o padrão de dominação colonial fundado nas hierarquias raciais ainda segue em operação. A primeira parte do artigo tematiza a instrumentalização do Direito como garantidor do lugar da branquitude, e como sustentáculo do racismo estrutural. O segundo tópico mostra como as normas migratórias foram utilizadas ambivalentemente como instrumento de controle e de racialização de vidas negras, e de manutenção de privilégios para o grupo racial dominante no Brasil.

Palavras-chave: Direito. Branquitude. Imigração. Racismo estrutural.

\section{"A MÃO QUE AFAGA É A MESMA QUE APEDREJA" [THE HAND THAT CARESSES IS THE SAME THAT THROWS STONES]: LAW, IMMIGRATION AND THE PERPETUATION OF STRUCTURAL RACISM IN BRAZIL}

\begin{abstract}
Based on the premise that Law is a technology for the control and racialization of black bodies (ALMEIDA, 2018), and for the maintenance of elites in power (PIRES, 2019) this article aims at showing how whiteness, as a place of

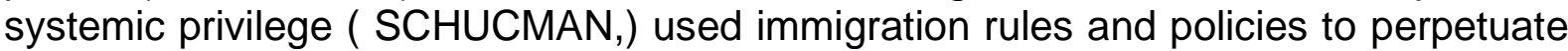
the unilateral advantages of structural racism. The theoretical basis is based on anticolonial, post-colonial and decolonial studies because they allow us to understand how the pattern of colonial domination founded on racial hierarchies is still in operation. The first part of the article deals with the instrumentalization of Law as a guarantor of the place of whiteness, and as a support for structural racism. The second topic shows how migratory norms were used ambivalently as an instrument to control and racialize black lives, and to maintain privileges for the dominant racial group in Brazil.
\end{abstract}

Keywords: Law. Whiteness. Immigration. Structural racism.

\section{INTRODUÇÃO}

O racismo estrutural é um regime que oprime as pessoas racializadas como não brancas à custa da produção e garantia de benefícios sistêmicos para sujeitos

\footnotetext{
${ }^{1}$ Augusto dos Anjos. Versos Íntimos. 1982.

2 Professora permanente dos Programas de Pós-graduação Stricto Sensu em Relações Internacionais e em Direito da Universidade Federal de Santa Catarina. Pesquisadora Produtividade em Pesquisa PQ CNPq. Doutora em Direito Internacional/UFSC. Realizou Estágio pós-doutoral na Katholieke Universiteit Leuven e Estágio Sênior na Université Libre de Bruxelles, Bélgica. É coordenadora do "EIRENĖ - Centro de Pesquisas e práticas Decoloniais e Pós-coloniais aplicadas às Relações Internacionais e ao Direito Internacional", da Cátedra Sérgio Vieira de Mello /ACNUR UFSC, e do Núcleo de Estudos Críticos de Raça e Interseccionalidades nas Relações Internacionais e no Direito Internacional. Este trabalho foi realizado com financiamento do CNPq.
} 
brancos. Este sistema alimenta e é alimentado por relações sociais, normas e instituições. Partindo da premissa segundo a qual o Direito é uma tecnologia de controle e racialização de corpos negros (ALMEIDA, 2018), e de manutenção de elites no poder (PIRES, 2019) este artigo objetiva mostrar como a branquitude, enquanto lugar de privilégio sistêmico (SCHUCMAN,) se utilizou de normas e políticas migratórias para perpetuar as vantagens unilaterais do racismo estrutural. A base teórica deste texto está assentada nos estudos anti e pós-colonais e decolonais porque estes permitem entender como o padrão de dominação colonial fundado nas hierarquias raciais ainda segue em operação. A primeira parte do artigo tematiza a instrumentalização do Direito como garantidor do lugar da branquitude, e como sustentáculo do racismo estrutural. O segundo tópico mostra como as normas migratórias foram utilizadas ambivalentemente como instrumento de controle e de racialização de vidas negras, e de manutenção de privilégios para o grupo racial hegemônico. No pano de fundo, vê-se quem são os corpos bem-vindos e bemacolhidos por um lado e, por outro, os que são rejeitáveis, exploráveis, e que circulam em condição de subalternidade. A crítica à branquitude é um exercício incômodo, mas necessário para avançarmos na promoção de justiça racial e na rehumanização de sujeitos que foram coisificados pelo empreendimento colonial. Para isso, é imperativo que corpos brancos e não brancos se reúnam em aliança para potencializarem forças, afetos e estratégias de desalienação. Corpos entrelaçados se transformam em lutas capazes de produzir futuros diferentes e novas formas de sociabilidade fundadas na humanização, de fato, coletiva.

\section{DIREITO, BRANQUITUDE E RACISMO ESTRUTURAL NO BRASIL}

Antes de evidenciarmos o lugar das normas e práticas jurídicas na sustentação do racismo estrutural é necessário tecer algumas considerações preliminares: em primeiro lugar, é fundamental atestar a ambivalência do Direito. Isto significa que o Direito pode ser um instrumento de emancipação mas, também, pode figurar como um mecanismo de opressão. Em segundo lugar, é fundamental advertir que para versar sobre opressões e desnudar privilégios, é inescapável trazer alguns incômodos, algumas contra-narrativas e insurgências como forma necessária não 
apenas para desnaturalizar os lugares de vantagens que, por consequência, provocam subalternizações mas, também, para resgatar a importância de transformar o Direito em um dispositivo eficiente para a construção de um mundo novo onde todas diversidades, sejam, em sua complexidade, respeitadas e humanizadas. Mas para produzir uma nova sociabilidade é fundamental, como aconselha Aimé Cesaire, "retirar os esqueletos do armário", isto é expor as dores dos "condenados da terra" (FANON, 2005) o que, por consequência, pode provocar o desconforto no grupo hegemônico. Ou seja, o que faço aqui é denunciar e me insurgir contra todo o sistema que nos oprime e nos desumaniza e, por outro lado, reivindico o potencial emancipatório do Direito. Em terceiro lugar, é imperativo entender que os Direitos Humanos são um campo em disputa. Há disputa de narrativas, entre visões de mundo, de ocupação de lugares, de conteúdo e de amplitude. E, por último, vale evidenciar que Direito não se resume às normas, ou relações de poder, já que contempla o complexo das relações sociais em sua amplitude.

O racismo estrutural é um regime que está escorado em pilares de privilégios do grupo dominante que se utiliza, dentre outros, de normas e instituições para se manter no topo da pirâmide social. Ou seja, racismo tem a ver com disputa de poder e distribuição de recursos. Isso quer dizer que o racismo não é apenas um ato isolado que se encerra nas fronteiras das relações intersubjetivas. É um sistema de opressão, de silenciamento e de exclusão. Grada Kilomba afirma que o "racismo não é um problema pessoal, mas um problema branco estrutural e institucional que pessoas negras experienciam" (2019, p. 204). O conceito de racismo estrutural nos dá a possibilidade de entender que todas as relações sociais, políticas, econômicas e institucionais no Brasil são atravessadas pela raça. Assim, o racismo não é apenas um recorte, algo lateral nas nossas relações. Ele é o elemento central das desigualdades vigentes no Brasil, é princípio estruturador e estruturante das nossas relações (ALMEIDA, 2018).

A origem deste sistema está na ocupação colonial europeia na América que produziu um catálogo complexo de identidades hierarquizadas com base na raça 
(QUIJANO) e no gênero (LUGONES, 2008). Daí surgem as representações e os binarismos civilizado-bárbaro, racional-irracional, bonito-feio, etc., e todas a cadeia de associação derivada destes essencialismos. As hierarquizações serviram para colonizar, sequestrar, traficar os seres humanos e escravizá-los. Este esquema infame foi providencial para a expansão do capitalismo racial, para garantir o enriquecimento e o bem-estar da Europa e o seu protagonismo nas Relações Internacionais que perdura até hoje, diga-se de passagem. O capitalismo mostra-se racial, segundo Cedric Robinson, porque ele se fundou na escravidão, na invasão, na expropriação, no genocídio e no imperialismo e, também, na hierarquização de pessoas. Ele explora quem racializa e racializa quem explora (ROBINSON, 2018).

O Direito Internacional surgiu no citado contexto histórico e desempenhou, com grande maestria, a função de homologar o colonialismo e a escravidão (MUTUA, 2000). Hugo Grotius, um dos fundadores do Direito Internacional, defendia literalmente que "há homens naturalmente escravos, isto é, nascidos para a escravidão, de igual modo há povos que lhes é mais natural obedecer do que governar" (GROTIUS, 2002, p. 179). Aliás, este ramo do Direito esteve todo o tempo empenhado em defender tanto a soberania, como a expansão dos Estados colonizadores, validando o discurso de uma pretensa missão civilizadora do ocidente.

Entretanto, o que eram ideias esparsas ganham robustez e sistematização entre o fim do século XIX e início do XX quando florescem as teses do chamado racismo científico. Como bem adverte Kabengele Munanga (2003), essa ideologia, como tantas outras, "esconde uma coisa não proclamada: a relação de poder e de dominação". O fim do século XIX é período da partilha da África. Portanto, o racismo foi a ideologia sustentadora do neocolonialismo que, por sua vez, foi instrumentalizado por marcos regulatórios elaborados pelos próprios colonizadores.

O racismo se baseia na ideia de superioridade intelectual, moral, física e estética dos brancos. Esse ideário continua a ser basilar para entender o sistema de hierarquizações e de controle do poder por este grupo dominante. Guerreiro Ramos 
(1957, p. 175), na década de 1950, observou que "para garantir a espoliação, a minoria dominante de origem europeia recorria não somente à força, à violência, mas a um sistema de pseudojustificações, de estereótipos ou um processo de domesticação psicológica".

Vários autores e autoras afro-diaspóricos, há muito tempo, já haviam denunciado a continuidade da dominação e das hierarquias fabricadas durante o período colonial (NASCIMENTO, 1980; GONZÁLEZ,1988; FANON, 2005). Segundo Aníbal Quijano, este padrão de dominação, que ele denomina de colonialidade, se manifesta tridimensionalmente, nos âmbitos do saber, do ser e do poder. Ele acrescenta que a ideia de raça tem sido "o mais eficaz instrumento de dominação social inventado nos últimos 500 anos" e o racismo é "sem dúvida, a mais perceptível e onipresente manifestação da colonialidade do poder" (QUIJANO, 2011). Isso significa que as nossas subjetividades, a produção e reprodução do conhecimento, bem como as maquinarias institucionais ainda seguem funcionando a partir daquela lógica de superioridade moral, intelectual e estética de brancos.

O Direito brasileiro, que ocupou função central para validar o colonialismo e a escravidão, continuou jogando um papel fulcral na manutenção desta colonialidade fundada na raça e no gênero, e tem exercitado esse seu poder por meio da racialização, do controle e da criminalização dos corpos negros. É conveniente frisar que a escravidão neste país foi racial, uma vez que os brancos não eram passíveis de escravização. O Direito colonial deu todo o suporte à escravidão racial e a todas as violências correlatas, como estupros, torturas, assassinatos, cerceamento de liberdades individuais e coletivas e do direito à educação e à formação de núcleo familiar (PRUDENTE, 1988), exploração do trabalho, etc.

O medo de repetição aqui dos levantes revolucionários que desembocaram na Revolução Haitiana foi refletido na Constituinte de 1823 (QUEIROZ, 2017), e gerou o recrudescimento de atos institucionalizados contra negros brasileiros e africanos, além de diversas tentativas de controlar e criminalizar ainda mais os indivíduos racializados. Essas violências serviram para reforçar a objetificação, para anular a 
dignidade e empurrar esses corpos para a "zona do não ser" (FANON, 2008). Mas, após a proclamação da República as elites brancas formularam e se serviram de discursos, práticas e normas fundadas na hierarquização racial para assegurarem a permanência hegemônica nos postos de decisão da nação no pós-Abolição da Escravatura. Ou seja, para manter a supremacia branca nas instâncias de poder era necessário hierarquizar o negro que, em tese, acabara de sair da condição de bem móvel, de coisa, de objeto e passara à condição de sujeito.

Nesse panorama, foi concebido um verdadeiro catálogo de normas discriminatórias que impuseram a proibição do ingresso de africanos no Brasil (Decreto 528 de 1890), a constitucionalização da eugenia em 1934, a criminalização da capoeira e perseguição às religiões de matriz africana, etc., o que demonstra a continuidade de um regime que instituiu o controle dos corpos e das mentes. A vadiagem e a mendicância ${ }^{1}$, que foram primeiramente tipificadas no artigo 295 do Código Criminal de 1830 no contexto do Haitianismo, foram reproduzidas na qualidade de contravenções no Código Penal brasileiro de 1890 e, portanto, eram medidas destinadas aos recém-libertos que se encontravam jogados nas ruas à própria sorte (ROORDA 2017). Ou seja, esse aparato normativo nasceu para controlar a circulação e, obviamente, para punir os corpos racializados ${ }^{2}$ que eram vistos como um problema de segurança pública pelas elites republicanas após a "libertação". Nesta esteira, podemos citar, também, a Lei de Contravenções Penais de 1941 (Decreto Lei 3.688 de 1941) que reforçou o entendimento de periculosidade de vadios e mendigos, e impôs a pena de prisão e a internação "em colônia agrícola ou em instituto de trabalho, de reeducação ou de ensino profissional". Assim, a higienização dos espaços urbanos foi uma das estratégias para criminalizar, penalizar e excluir corpos negros que foram a imensa maioria dos afetados por essas normas.

Houve, assim, uma política repressiva de Estado vocacionada para aniquilar corpos

\footnotetext{
${ }^{1}$ Estes dispositivos que criminalizam a mendicância e vadiagem foram revogados pela Lei de $\mathrm{n}^{0}$ 11.983 , de 2009.

2 Ainda que os brancos também constituam uma raça, utiliza-se o termo racializado aqui para enfatizar a hierarquização de pessoas não brancas.
} 
pretos. A tese preponderante no início da República era a de promover a extinção dos negros da sociedade, como se pode verificar nas palavras de João Batista Lacerda (1911):

\begin{abstract}
Após a abolição o negro deixado à própria sorte, começa a deixar os grandes centros civilizados, fugindo do movimento e progresso ao qual ele não pôde se adaptar. Vivendo uma existência quase selvagem, sujeita a todas as causas de destruição, sem recurso suficiente para se manter, resistente a qualquer disciplina, o negro se espalha em regiões pouco povoadas e tende a desaparecer do nosso território, como uma graça destinada à vida selvagem e rebelde à civilização.
\end{abstract}

Nesse sentido de provocar exclusão dos corpos marginalizados, é que as políticas migratórias serviram, historicamente, como uma das armas de guerra contra indivíduos não brancos neste país. Ademais, elas são exemplos fundamentais para entender como o Direito racializou e promoveu o controle dos negros e das negras, e também operou para manter a branquitude no poder, consoante será explicitado na sequência.

\title{
3. MIGRAÇÃO BRANCA COMO MEIO DE CONTROLE, RACIALIZAÇÃO E MANUTENÇÃO DE PRIVILÉGIOS
}

A higienização e o controle de pessoas marcadas racialmente via legis não se deu apenas no âmbito interno, mas também incluiu estratégias de projeção internacional que serviram para atrair imigrantes brancos para se assentarem no Brasil e, por outro lado, para rejeitar e punir africanos e afro-diaspóricos. Para tal, desde o Império houve a aprovação de normas migratórias baseadas integralmente na estratificação racial, e que favoreceram o ingresso e a concessão de privilégios para populações brancas cujos reflexos são sentidos até a contemporaneidade. A seguir, são colecionados apenas alguns exemplos ilustrativos que comprovam que o Estado concebeu uma verdadeira política de ações afirmativas para coletivos brancos, que incluiu desde o apoio para realização do trajeto para chegada no Brasil, até a cessão de terras, e ofertas de outras condições favoráveis para integração no país. 
Por meio da Carta Régia de 23 de setembro de 1811, o Império concedeu terras para o estabelecimento de uma colônia de irlandeses no Rio Grande do Sul e autoriza a "demarcação de uma grande extensão de terreno que deverá ter dez legoas e meia quadradas ou tres e um quarto de raiz ou lado, em sitio junto de algum rio navegavel, até o mar, e que não seja totalmente areento" (grifo nosso).

Outro exemplo é o Decreto de 16 de maio de 1818 que estabelece as condições para o assentamento de uma colônia suíça formada por 100 famílias no Rio de Janeiro e que formalizou as seguintes ofertas: pagamento de despesas de transporte para toda a família, além de alojamento provisório construídos especialmente para acolhê-los até a sua instalação definitiva. Além cada família suíça teve direito a:

sem pagar renda ou pensão alguma, uma determinada porção de terra, e além disso animaes, ou sejam bois, cavalos, ou machos de puxar, vaccas, ovelhas, cabras,e porcos; e para plantar e semear distribuir-se-lhes-ha trigo, feijões, favas, arroz, batatas, milho, semente (...); em fim receberão viveres em especie ou em dinheiro durante os dous primeiros anos do seu estabelecimento.

Art. $5^{\circ}$ Dignando-se Sua Magestade de conceder a cada colono suisso 160 réis por dia, e por cabeça, pelo primeiro anno de sua habitação no Brazil e 80 reis pelo segundo (...)

Esses são exemplos claros de privilégios baseados na racialização operada por meio do Direito, uma vez que, no mesmo período histórico, se estipulava, paradoxalmente, a condição de objeto para povos negros e se considerava o branco como pessoa digna de humanidade. Esse tratamento diferenciado se dá por conta de raça. Aliás, os brancos não apenas eram humanos, mas mereciam concessões e favorecimentos que Ihe eram oferecidos pelo Estado à custa do trabalho escravo que provia enriquecimento para as elites nacionais, alimentava o erário e gerava ganhos para os imigrantes brancos que aqui chegavam.

As leis de imigração também serviram como forma de controle para impedir a entrada dos corpos negros no Brasil. Veja, por exemplo, o já citado Decreto nํ 528 
de 28 de junho de 1890, que determinou, no alvorecer da República, a completa interdição ao ingresso de não brancos:

Art. $1^{\circ} \mathrm{E}^{\prime}$ inteiramente livre a entrada, nos portos da Republica, dos indivíduos válidos e aptos para o trabalho, que não se acharem sujeitos à acção criminal do seu pais, exceptuados os indígenas da Asia, ou da África que somente mediante autorização do Congresso Nacional poderão ser admittidos de accordo com as condições que forem então estipuladas. (grifo nosso)

O governo brasileiro fecha mais o cerco na década de 1920 quando passou a se utilizar de medidas executivas, legislativas e diplomáticas para proibir o ingresso de estadunidenses negros no país, ao mesmo tempo em que subsidiava a admissão de milhares de europeus (PEREIRA 2010; NASCIMENTO, 1978). Foi diante de iniciativas de um grupo de negros de Chicago de emigrarem para o Brasil, na tentativa de escaparem das violências provocadas pelas leis Jim Crow, que se abriu aqui um debate parlamentar caloroso com vistas a extirpar quaisquer empreendimentos nesse sentido. O deputado mineiro Fidélis Reis propôs, em 1923, a restrição absoluta de imigrantes negros de todas as nacionalidades argumentando que os afro-estadunidenses seriam uma "perturbação para a paz". Oliveira Vianna, em apoio a Reis, aduzia que os afro-americanos eram altivos, agressivos e segregacionistas, e o "black nationalism" seria um "perigo político", uma grande ameaça para a nossa jovem República. (RAMOS, 1986, p. 65-66). Nesse contexto de debates, Afrânio Peixoto apresenta o seu veredicto:

É neste momento que a América pretende desembaraçar-se do seu núcleo de 15 milhões de negros no Brasil. Quantos séculos serão precisos para depurar-se todo esse mascaro humano? Teremos albumina bastante para refinar toda essa escória? Não bastou a Libéria, descobriram o Brasil? Ainda com armas na mão, não, não e não! Deus nos acuda, sé é brasileiro! (CÂMARA DE DEPUTADOS, 1923, p. 383-384)

Na década de 1930, no auge das teses do racismo pretensamente denominado de científico, as políticas são mais incisivas contra o ingresso de imigrantes negros e, portanto, especificam mais claramente o critério eugênico para a aceitação de 
imigrantes no Brasil ${ }^{3}$. O Decreto-Lei no 406, de 4 de maio de 1938, estabelece que o "Governo Federal reserva-se o direito de limitar ou suspender, por motivos econômicos ou sociais, a entrada de indivíduos de determinadas raças ou origens" (grifo nosso). Dito isso, não precisaria explicar quem são as determinadas raças ou origens. Mas, ainda assim, em 1945, o Decreto-Lei no 7.967, não deixa dúvidas ao prescrever em seu artigo $2^{\circ}$ que: “Atender-se-á, na admissão dos imigrantes, à necessidade de preservar e desenvolver, na composição étnica da população, as características mais convenientes da sua ascendência europeia". (grifo nosso). Dado o exposto, resta clara a manutenção de privilégios e instituição de controle baseado na raça o que, por outro lado, evidencia quais são os corpos que são bem-recebidos, desejáveis e amáveis. (BORBA DE SÁ; SILVA, prelo). Ou seja, "a mão que afaga é a mesma que apedreja". (ANJOS, 1982)

Neste sentido, Eunice Prudente (1988) observa que "o Direito brasileiro exerceu funções distintas com referência aos dois grupos" de imigrantes: os brancos foram destinatários de um aparato de leis migratórias benéficas com vistas a integrar a família no Brasil e à promoção da dignidade humana, tais como direito ao salário, à educação, à proteção do núcleo familiar, o reconhecimento da religião protestante, etc; os negros eram considerados objetos regulados por leis escravistas de caráter brutalmente punitivo, com a atribuição de penas de morte, da depreciação da identidade e da cultura, o impedimento à formação do núcleo familiar, cerceamento do direito de reunião e a perseguição de lideranças. O objetivo das leis era o de "dividir para submeter". Segundo a autora, "o sucesso do imigrante europeu e asiático dependeu, como se comprovou, da proteção às famílias imigrantes e das providências legais com vista à integração". A proteção do núcleo familiar foi elemento decisivo para o progresso econômico e social destas famílias, o que incidiu no desenvolvimento das regiões do país em que vivem atualmente os seus descendentes. Por outro lado, o desmantelamento dos laços familiares de africanos,

\footnotetext{
${ }^{3} \mathrm{O}$ estudo mais completo da legislação brasileira em perspectiva histórica encontra-se em BORBA DE SÁ, Miguel; SILVA, Karine, prelo.
} 
desde o sequestro em África, e a separação aqui no Brasil, aliado a tratamentos desumanos, provocou traumas sentidos até hoje.

Dito isso, não resta dúvidas que o branqueamento via leis migratórias foi uma estratégia "de genocídio institucionalizado, sistemático, embora silencioso" do povo negro no Brasil (NASCIMENTO, 1978). As políticas migratórias e o conjunto de leis que as compunham objetivavam reduzir os contingentes negros e impulsionar a mestiçagem de modo que - como defendeu o único representante brasileiro no Congresso Internacional de Raças em Londres em 1911, João Batista Lacerda - as correntes de imigração europeia aumentariam progressivamente o elemento branco na população o que levaria, por consequência, à extinção dos traços negros. Segundo ele, "em virtude deste processo de redução étnica, é lógico supor que no curso de mais de um século os mestiços tenham desaparecido no Brasil. Isto coincidirá com a extinção paralela da raça negra em nosso meio" (LACERDA, 1911, p. 18-19).

As legislações migratórias da segunda metade do século passado continuaram a impor diversas restrições para a admissão de africanos e afro-diaspóricos. Por outro lado, é crucial fazer jus à Constituição de 1988 que estampou a face emancipadora do Direito pois, além de reconhecer o direito à ancestralidade e às comunidades quilombolas o direito à terra, consagra, no seu artigo $4^{\circ}$, o repúdio ao racismo como princípio orientador da atuação do Brasil nas Relações internacionais e, no artigo $5^{\circ}$, a igualdade entre brasileiros e estrangeiros. Porém, a própria Carta Magna, no seu artigo 12, oferece apenas aos portugueses, os antigos colonizadores, os privilégios do Estatuto da Igualdade ${ }^{4}$. Nesta mesma esteira, surge a nova Lei de Migração (13.445/2017) que, embora tenha chegado tardiamente, se revela como uma norma que serve de exemplo internacional de proteção migratória. Entretanto, a Lei 13.445 peca por universalizar a pessoa imigrante e não assumir que os que aqui chegam partem de lugares geográficos, sociais e raciais diferentes. Os corpos brancos do Norte global ainda são lidos e acolhidos aqui diferentemente dos corpos racializados como não brancos. A raça e as suas intersecções com o gênero e sexualidades

${ }^{4}$ Concessão de igualdade de Direitos e Obrigações Civis e Gozo de Direitos Políticos. 
dificultam a entrada e permanência e vulnerabilizam a condição de existência das vidas negras. $O$ Direito tem obrigação de corrigir estas inequidades nesta nação que tem uma dívida histórica com os povos africanos/as e os da diáspora. Fato é que, até hoje, mesmo com a vigência da nova lei de Migração, são esses os coletivos que têm mais dificuldade de regularização migratória e de acesso a direitos humanos no Brasil.

Do exposto se afirma que migração é um tema atravessado pela raça. As políticas migratórias brasileiras perpassadas pela eugenia, não só mantiveram a ideia de supremacia racial do branco, como concederam inúmeros privilégios a imigrantes brancos, - como concessão de terras, oportunidades de trabalho, etc., (BORBA DE SÁ; SILVA, prelo). Ou seja, as políticas migratórias brasileiras foram uma máquina de privilégios para a branquitude. E, como visto, atestam para a funcionalidade do Direito tanto na manutenção destes benefícios, como também na racialização do sujeito negro.

O sul do Brasil é um "case de sucesso" da política de embranquecimento e de concessão de vantagens a imigrantes que aqui chegaram. Não é à toa que a "Europa brasileira" ostenta índices de desenvolvimento mais elevados do que a média nacional. Mas é claro que é necessário questionar esse modelo de desenvolvimento excludente porque as pessoas negras desta parte do Brasil vivem em condições muitos mais desfavoráveis que as pessoas brancas. Aliás, em Santa Catarina, por exemplo, abundam propagandas orgulhosas sobre a sua "identidade europeia", enquanto que a contribuição de negros e indígenas na construção e enriquecimento deste estado segue apagada (SILVA, MULLER, MARTINS, 2018).

Não se pode entender a migração forçada de africanos sem relacionar tanto os favorecimentos que o tráfico aportou - e continua, por herança, aportando - para as pessoas brancas nesta nação, quanto os benefícios que as leis migratórias embranquecedoras trouxeram para os destinatários da mesma raça. Ou seja, os privilégios têm a ver com a intersecção entre migração e raça, e geraram consequências que se perpetuam tanto no âmbito nacional como internacional. $O$ 
Tráfico Atlântico, que foi a maior tragédia de mobilidade humana da história, produziu muita riqueza para Europa e para os Estados Unidos. Pesquisas do "Centre for the Study of the Legacies of British Slave-Ownership" lideradas pelo Professor Matthew Smith da University College London têm mostrado como os escravistas britânicos e seus descendentes se beneficiaram financeiramente com o tráfico de africanos e africanas. Estes estudos provam que a pujança material e bem-estar das sociedades europeias estão calcados, em grande medida, no colonialismo e na escravidão. (https://www.ucl.ac.uk/lbs/project/)

No Brasil, a escravidão racial produziu uma elite, cujos descendentes ainda continuam sendo os donos do poder. As políticas migratórias pós-abolição mobilizaram recursos públicos retirados de camadas pobres e escravizadas para financiar o ingresso de imigrantes europeus, e ainda hoje se vê como os benefícios documentais ou financeiros favoreceram o assentamento e ascensão sócioeconômica destas pessoas. Nesta altura, vale frisar que este não é um manifesto contra a imigração branca e europeia, pois entendemos que a migração é um direito humano. Do mesmo modo, não significa que imigrantes brancos não tenham sofrido muito nos seus processos migratórios e de assentamento. Trata-se de uma lembrança que todos os serem humanos merecem ser tratados com dignidade, e que as políticas afirmativas migratórias para brancos foram uma alavanca de privilégios para a branquitude.

Mas não se pode entender as políticas de concessão de privilégios sem mencionar que as Faculdades de Direito, com grande destaque para as de Recife e São Paulo, jogaram um papel crucial na produção e propagação das teorias raciais no alvorecer do Estado republicano brasileiro. Foi nessas faculdades, assim como nas de Medicina e nos museus (etnográficos, históricos e geográficos) que surgiu e que se consolidou o modelo eugênico de Estado, um tipo amoldado que gerou uma eugenia à brasileira (SCHWARTZ, 1933), e que produziu um embranquecimento via legis. A eugenia precisa ser vista como uma reação violenta contra os movimentos abolicionistas. Como continuamente ocorre no percurso histórico, sempre que há uma onda progressiva, há uma resposta reacionária. 
As Faculdades de Direito no século XX eram encarregadas de formar uma elite intelectual neste país. Esta, com o fim da escravidão, se empenhou em fundar um novo regime político e, sobretudo, a fomentar mecanismo para se manter no topo da hierarquia social. Nesta nova ordem, os ex-escravistas, quer dizer, a elite branca, precisava encontrar formas de permanecer no controle do poder. Para tal, era necessário resolver o "chamado problema do negro". Foi aí que a discursividade eugênica europeia anti-negra ganhou força com as teses desenvolvidas nas Faculdades de Direito que, como afirmado, se destinavam a perpetuar o poder nas mãos dos antigos escravistas. As ideias e estudos jurídicos se transformaram em um aparato legislativo e jurisdicional, na medida em que os egressos dos cursos se tornavam legisladores e operadores do Direito. Foi neste contexto de afirmação da eugenia que surgiu a ideia de promover a imigração branca, ao mesmo tempo que a de interditar o ingresso de populações negras e amarelas, consideradas como selvagens e perigosas. Nas mãos desta intelligentsia estava a função de produzir a imagem da jovem República que se queria branca e "civilizada" e, para tal, era necessário formular leis que ativasse uma "nova consciência". (SCHWARCZ, 2012)

Ou seja, as Faculdades de Direito são uma pedra angular do racismo estrutural, seja por meio da concepção de normas que promoveram a racialização e controle dos corpos negros, seja pela formatação dos quadros predominantemente brancocêntricos que sempre compuseram o legislativo e judiciário deste país. Desta feita, a história das Escolas de Direito é contundentemente atravessada pelo racismo, uma vez que elas produziram teorias geradoras de políticas e normas patrocinadoras do embranquecimento da nação (SCHWARCZ, 2012), e que, por conseguinte, têm operado para promover o genocídio do povo negro brasileiro. (NASCIMENTO, 1978)

É importante resgatar essa parte esquecida da história das careiras jurídicas do Brasil. Dos cursos de Direito sempre saíram políticos, ministros, governadores, senadores e deputados, embaixadores, juristas e pensadores que têm ditado os rumos da nação e perpetuado, voluntaria ou involuntariamente, estratégias de 
controle social de pessoas negras. Tais elites intelectuais e de direção política, não por acaso, são alguns dos descendentes de imigrantes brancos seja da primeira corrente migratória europeia, seja das posteriores que trouxeram outras nacionalidades que se beneficiaram, e continuam se beneficiando dos privilégios normalizados e normatizados da branquitude no Brasil.

Toda essa trajetória de normas e políticas públicas executadas durante séculos produzem reflexos devastadores até hoje, como o encarceramento em massa, a pobreza racializada, o alto índice de letalidade de jovens negros, os baixos níveis de acesso à educação, aversão a imigrantes afro-diaspóricos, etc., e, sobretudo, a subrepresentação de pessoas negras em todos os espaços de poder. É claro que a subrepresentativide é um aspecto do controle dos corpos.

Conforme mencionado anteriormente, o racismo é um sistema de exclusão, silenciamento e opressão. Entretanto, é necessário mudar a chave para entender o outro lado da moeda que é o lugar da branquitude. Segundo Lia Schucman, a branquitude é "um lugar de poder, de vantagem sistêmica nas sociedades estruturadas pela dominação racial" (p. 102). Ou seja, o mesmo dispositivo que gera desvantagens de um lado, desengatilha vantagens do outro. Conforme visto, o Direito e as instituições jurídicas, em grande medida, concorrem para assegurar benefícios ao grupo dominante, apenas pela pertença racial branca.

Assim resta provado que a branquitude é um disparador de desigualdades (SCHUCMAN, 2012). Neste país alicerçado em arranjos oligárquicos que obstruem as vias de mobilidade social de não brancos, se vê a perpetuação de pessoas brancas em caráter majoritário ocupando todos os setores do poder, sobretudo, na esfera jurídica, seja na docência do Direito, na magistratura, no Ministério Público, etc, e isso produz consequências sociais. Trata-se de um lugar de privilégio que se configurou por conta do racismo estrutural e das antigas políticas geradoras de benefícios. 
Assim, uma das consequências do tratamento diferenciado que migrantes do Norte Global receberam no Brasil é a manutenção continuada destes sujeitos no poder, o que, por consequência, opera para a perpetuação do racismo institucional. Conforme suscitado anteriormente, o racismo tem a ver com poder e com Direito. E as Instituições, por seu turno, são lugares, por excelência, de luta por hegemonia, por lugares de poder (ALMEIDA, 2018), onde há tensionamentos para imposições de visões de mundo, de valores de determinados grupos, e obviamente, há disputas pela distribuição de recursos. Nelas, operam, com muita força, tanto o racismo intersubjetivo como institucional, duas das faces do modelo estrutural. Isso quer dizer que os obstáculos para ingresso nos altos postos de comando e, no caso do tema específico deste artigo, nas carreiras jurídicas são, principalmente, de ordem estrutural, como, por exemplo, os óbices para o acesso à educação superior, entre outras dificuldades materiais que impedem jovens negros e negras de serem aprovados nos concursos.

A falta de representatividade de negros e negras no sistema de justiça e na docência é um problema visível em todos os âmbitos, seja na advocacia, na magistratura, no Ministério Público, nas Universidades, etc.. Segundo dados coletados no Censo do Conselho Nacional de Justiça de 2018, a magistratura brasileira é branca e masculina. O Censo apurou que $80,3 \%$ dos magistrados são brancos. Os negros correspondem a apenas 18\% (16,5\% pardos e 1,6\% pretas), 1,6\% dos/as juízas são de origem asiática e somente 11 magistrados se declararam indígenas, menos de 1\%. (CNJ, 2018).

O racismo estrutural está transparente quando se percebe, ainda segundo o $\mathrm{CNJ}$, que $33 \%$ dos juízes possui pai ou mãe na Magistratura, o que revela um alto grau de endogenia na carreira, e mais da metade dos entrevistados tem familiares em outras carreiras do Direito (51\%). Além do racismo, há o sexismo: apenas $37 \%$ dos juízes brasileiros são mulheres. As intersecções de gênero e raça desabam sobre as mulheres negras, pois são as que aparecem em menor número na magistratura e, como em todas as outras esferas no Brasil, são as mais afetadas pelo racismo sistêmico. Os dados também dão conta que a diversidade étnico-racial é um pouco 
maior na Justiça do Trabalho em comparação às Justiças Estadual e Federal (CNJ, 2018).

Em Santa Catarina, estado extremamente beneficiado pelas políticas migratórias, a magistratura estadual é a mais branca do Brasil, perfazendo um montante de 97\%. Os juízes pretos e pardos são menos de 3\% do grupo, e cerca de 1\% são amarelos e indígenas. O Piauí tem o judiciário menos branco mas, ainda assim, perfaz 54\% dos entrevistados. Os pretos e pardos são $45 \%$ e os indígenas e amarelos são $1 \%$ do corpo de magistrados. Mas, em geral no país, a Justiça estadual é composta por $80 \%$ de pessoas brancas, $18 \%$ são pretas e pardas, e $1 \%$ são amarelas e indígenas (CNJ, 2018).

No Legislativo, onde são elaboradas as normas que são aplicadas pelo sistema de Justiça, e que devia ter a sua composição mais equilibrada, já que essa representação é eleita por voto popular, os números são reveladores da estruturação do racismo: entre os 81 senadores da República, apenas 03 são pretos. Os deputados brancos são $75 \%$ da Casa.

A situação se repete na docência jurídica, pois professores negras e negros são a minoria nas Faculdades de Direito. Aliás, o Censo da Educação Superior do INEP revela que entre os professores universitários de todas as áreas, só $16 \%$ se consideram negros.

A sobre-representatividade dos brancos é um resultado do racismo estrutural que concede privilégios a um grupo e impede que outros ocupem espaços de poder e decisão. Os dados acima levantados revelam que o Direito ainda hoje é formulado, aplicado e ensinado a partir de uma lógica brancocentrada masculina e isso impacta no exercício da jurisdição, e da distribuição de justiça social e racial. Esta perspectiva unilateral por si só não dá conta de compreender as complexidades sociais brasileiras, compostas por muitas camadas. 
A subjetividade dos brancos em um país de racismo estrutural é marcada pela branquitude, assim como a dos negros é marcada pelo racismo (SCHUCMAN, 2012) e isso pode gerar consequências na hora de julgar, de defender, de formular lei. $O$ privilégio que coloca o branco em um lugar de vantagem estrutural tende a se refletir quando o juiz julga e o promotor acusa pois, possivelmente, eles reproduzirão essa visão de mundo.

O déficit de representatividade implica déficit democrático e de legitimidade de decisões que são tomadas apenas por pessoas de um segmento racial-social, não espelhando a diversidade sócio-econômica e racial brasileira em sua complexidade, e impede a eficiência do Estado porque ele deve atender à sociedade como um todo. Isto explica em parte, por exemplo, os números abusivos do encarceramento de pessoas negras, os quais são um resultado, dentre outros, desta maquinaria predominantemente elitista, patriarcal e brancocentrada. Isso explica, também, os entraves formais e informais que imigrantes racializados encontram para se regularizarem no Brasil e para acessarem os seus direitos. As violências institucionais, os inúmeros casos de mortes evitáveis de recém-nascidos de mulheres imigrantes e de injúria racial revelam, sem disfarce, como a necropolítica estatal escolhe esses coletivos. Isto mostra que o passado colonial é atemporal, pois ele é reencenado cotidianamente e tem caráter de readaptação no decorrer dos tempos (KILOMBA, 2019).

\section{CONSIDERAÇÕES FINAIS}

O exposto revela, em primeiro plano, que a hospitalidade brasileira é seletiva, pois nomeia e elege corpos que são merecedores de abrigo e proteção e, por outro lado, os que são passíveis de rechaço, de controle e desassistência. Em segundo plano, vê-se que ainda hoje, voluntária ou involuntariamente, a sociedade perpetua o ideal de superioridade moral, intelectual e/ou estética dos brancos. Em terceiro lugar, fica evidente como a branquitude se utilizou de normas e políticas migratórias, verdadeiras ações afirmativas, para manutenção no poder e para garantir benefícios 
sistêmicos. As Instituições e normas operaram e operam para manter esse sistema de hegemonias.

A política de branquemento, do elogio à mestiçagem, juntamente com a tese mítica da democracia racial se configuraram, no tempo, como estratégias de manutenção do poder e de privilégios para sujeitos brancos. As propagandas que internacionalmente mostram o Brasil como país alegre e acolhedor, onde se celebra um verdadeiro festival de raças e nacionalidades, escondem as intersecções entre migração e raça, e que a branquitude instrumentalizou um discurso de tolerância universal para continuar imputando a si própria uma representação colonial de ilustração, de justeza e de defensora dos direitos humanos.

O Brasil se reconheceu oficialmente como país racista no contexto da Conferência de Durban, mas governos e sociedade ainda precisam avançar na pauta anti-racista. Para tal, é fundamental que se admita coletivamente a existência de privilégios e, sobretudo, que se aprimorem os mecanismos de distribuição equitativa de bens públicos.

É necessário, do mesmo modo, recuperar o potencial emancipatório do Direito. Ainda que Direito não seja sinônimo de Lei, pode-se levantar alguns exemplos de formas de como o Direito pode ser libertador, como é o caso da Lei de proteção ao trabalho doméstico, das Leis 10.635/2003 e 11.645/08, da Lei de Cotas no Ensino Superior e da própria Constituição Federal que incluiu o combate ao racismo como um dos seus princípios. O que está em pauta é a defesa do Direito como instrumento de resistência e emancipação. Esse é um exercício desconfortável, mas é crucial quebrar o silêncio para construirmos novas formas de sociabilidade a partir do desmantelamento das estruturas do racismo.

\section{REFERÊNCIAS}

ALMEIDA, Silvio. O que é racismo estrutural? Belo Horizonte (MG): Letramento, 2018.

ANJOS, Augusto dos. Eu \& Outros Poesias. V.1. Rio de Janeiro: Civilização/Itatiaia, 1982. 
BRASIL. CARTA RÉGIA DE 23 DE SETEMBRO DE 1811. Disponível em: https://www2.camara.leg.br/legin/fed/carreg sn/anterioresa1824/cartaregia-3986423-setembro-1811-570811-publicacaooriginal-93914-pe.html. Acesso em 15 de julho de 2019.

BRASIL. CÂMARA DOS DEPUTADOS. Anais da Câmara. Rio de Janeiro: Imprensa Nacional, 1923.

BRASIL. CONSELHO NACIONAL DE JUSTIÇA (CNJ). Perfil sociodemográfico dos magistrados brasileiros 2018. em: http://www.cnj.jus.br/files/conteudo/arquivo/2018/09/49b47a6cf9185359256c 22766d5076eb.pdf .Acesso em: 15 mar. 2020.

BRASIL. Constituição (1934). Constituição da República dos Estados Unidos do Brasil. Rio de Janeiro, 1934. Disponível em $<$ http://www.planalto.gov.br/ccivil 03/Constituicao/Constituicao34.htm> Acesso em 08 de abril 2019.

BRASIL. Decreto-Lei nำ 406, de 4 de maio de 1938. Dispõe sôbre a entrada de estrangeiros no território nacional. Diário Oficial da União, Rio de Janeiro, Brasil, 04 de Maio 1938 Seção 1 p. $8494 a$ Disponível em $<$ https://www2.camara.leg.br/legin/fed/declei/1930-1939/decreto-lei-406-4-maio1938-348724-publicacaooriginal-1-pe.html> Acesso em 08 de abril 2019.

BRASIL. Senado Federal. Lei 13.445, de 24 de maio de 2017. Brasília, 2017. Disponível em: <http://www2.camara.leg.br/legin/fed/lei/2017/lei-13445-24-maio2017-784925-publicacaooriginal-152812-pl.html>. Acesso em: 08 out 2019.

BRASIL. Decreto-Lei no 7.967, de 18 de setembro de 1945. Disponível em http://www.planalto.gov.br/ccivil 03/Decreto-Lei/1937-1946/Del7967.htm . Acesso em: 08 out 2019.

CÉSAIRE, Aimé. Discours sur le colonialisme. Paris. Éditions de l'AAARGH, 2006. BRASIL. Decreto de 16 de maio de 1818. Disponível em https://www.camara.leg.br/Internet/InfDoc/conteudo/Colecoes/Legislacao/legimpD 90.pdf . Acesso em 15 de julho de 2019.

FANON, Frantz. Os condenados da terra. Tradução de Enilce Albergaria Rocha e Lucy Magalhães. Juiz de Fora (MG): Editora da UFJF, 2005.

FANON, Frantz. Peles Negras, Máscaras brancas. Salvador: Ed. UFBA, 2008.

FARIAS, Marcio. Relatos de imigrantes africanos sobre preconceito na cidade de São Paulo. Dissertação (Mestrado em Psicologia Social) - Programa de Estudos Pós Graduados em Psicologia Social. Pontifícia Universidade Católica de São Paulo. São Paulo. 
GONZALEZ, Lélia. A categoria político-cultural de amefricanidade. Tempo Brasileiro. Rio de Janeiro, no. 92/93 (jan./jun.). 1988, p. 69-82.

GROTIUS, Hugo. O direito da guerra e da paz. Tradução de Ciro Mioranza. 2. ed. ljuí: Ed. Unijuí, 2002.

KILOMBA, Grada. Memórias da Plantação: episódios do racismo cotidiano. Trad. Jess Oliveira. Rio De janeiro: Cobogó, 2019.

LACERDA, João Baptista de. Congresso Universal das Raças. Rio de Janeiro: s.n. 1912.

LACERDA, João Baptista de. Sur le métis au Brésil. In: Premier Congrès Universel des Races: 26-29 juillet 1911. Paris: Devouge. 1911.

LUGONES, María. Colonialidad y género. Tabula Rasa, Bogotá, n. 9, p. 73-101, jul./dez. 2008.

MULLER, Tânia Mara Pedroso; CARDOSO, Lourenço. Apresentação In: Branquitude: estudos sobre a identidade branca no Brasil. Curitiba: Appris, 2017.

MUNANGA, 2003. Uma abordagem conceitual das noções de raça, racismo, identidade e etnia. Palestra proferida no $3^{\circ}$ Seminário Nacional Relações Raciais e Educação-PENESB-RJ, 05/11/03. Disponível em: https://www.geledes.org.br/wpcontent/uploads/2014/04/Uma-abordagem-conceitual-das-nocoes-de-raca-racismodentidade-e-etnia.pdf Acesso em 15 fevereiro 2010.

MUTUA, Makau. Critical Race Theory and International Law: The View of an InsiderOutsider. Villanova Law Review 45. P. 841-854, 2000.

NASCIMENTO, Abdias do. O Genocídio do negro brasileiro: processo de um racismo mascarado. Rio de Janeiro: Paz e Terra, 1978.

NASCIMENTO, Abdias do. O Quilombismo: documentos para uma militância panafricanista. Petrópolis: Vozes, 1980.

PEREIRA, Amílcar Araújo. "O Mundo Negro": a constituição do movimento negro contemporâneo no Brasil (1970-1995). 2010. 268 f. Tese (Doutorado) - Curso de História, Instituto de Ciências Humanas e Filosofia, Universidade Federal Fluminense, Niterói, 2010. Cap. 1. Disponível em: <http://www.historia.uff.br/stricto/td/1254.pdf>. Acesso em: 03 jun. 2019.

PIRES, Thula. Direitos humanos e Améfrica Ladina: Por uma crítica amefricana ao colonialismo jurídico. In: Viveros-Vigoya, Mara (Org.). Améfrica Ladina: Vinculando Mundos y Saberes, Tejiendo esperanzas. Guadalajara: LASA, 2019.

PRUDENTE, Eunice. A. de J. O negro na ordem jurídica brasileira. Revista Da Faculdade De Direito, Universidade De São Paulo, 83, 135-149, 1988. Disponível 
em: http://www.revistas.usp.br/rfdusp/article/view/67119 . Acesso em 15 de julho de 2019.

QUEIROZ, Marcos Vinícius Lustosa. Constitucionalismo brasileiro e o Atlântico Negro: a experiência constitucional de 1823 diante da Revolução Haitiana. 2017. 200 f., il. Dissertação (Mestrado em Direito) - Universidade de Brasília, Brasília, 2017.

QUIJANO, Aníbal. "! Que tal raza!'. Ecuador Debate, n. 48, 1999.

ROBINSON, CEDRIC J.. Racial Capitalism: The Non objetive Character of Capitalist Development. Tabula Rasa [online]. 2018, n.28, p.23-56.

RAMOS, Alberto Guerreiro. A Introdução Crítica a Sociologia Brasileira. Rio de Janeiro: Andes, 1957.

RAMOS, J. S. Dos males que vêm com o sangue: as representações raciais e a categoria do imigrante indesejável nas concepções sobre imigração da década de 20. In: MAIO, M.C., and SANTOS, R.V., Orgs. Raça, ciência e sociedade [online]. Rio de Janeiro: Editora FIOCRUZ; CCBB, 1996.

ROORDA, João Guilherme Leal. Criminalização da vadiagem na Primeira República: o sistema penal como meio de controle da população negra (1900-1910). Revista Brasileira de Ciências Criminais, v. 135, p. 269-306, 2017.

SÁ, Miguel Borba de, SILVA, Karine de Souza. Do Haitianismo à nova Lei de Migração: Direito, Raça e Política Migratória brasileira em perspectiva histórica. Prelo.

SCHUCMAN, Lia Vainer. Entre o "encardido", o "branco" e o "branquíssimo": raça, hierarquia e poder na construção da branquitude paulistana. 2012. Tese (Doutorado em Psicologia Social) - Instituto de Psicologia, Universidade de São Paulo, São Paulo, 2012.

SCHWARCZ, Lilia Moritz. O espetáculo das raças: cientistas, instituições e questão racial no Brasil 1870-1930. São Paulo: Companhia das Letras, 1993.

SILVA, Karine de Souza; MULLER, J.; SILVEIRA, Henrique M. Santa Catarina no roteiro das Diásporas: os novos imigrantes africanos em Florianópolis. Revista Katalysis, v. $21, \quad$ p. 281-292, 2018. Disponível em: https://www.scielo.br/scielo.php?script=sci arttext\&pid=S1414$49802018000200281 \& \operatorname{lng}=$ pt\&tlng=pt Acesso em 11 maio 2020. 